\title{
Acetonitrile-free organic electrolyte for textile supercapacitor applications
}

N Hillier ${ }^{1,2}$, S Yong ${ }^{2}$, A Cruden ${ }^{1}$ and S Beeby ${ }^{2, z}$

${ }^{1} \mathrm{CDT}$ in Energy Storage and its Applications, University of Southampton, SO17 1BJ, UK

${ }^{2}$ Smart Electronic Materials and Systems Group, University of Southampton, SO17 1 BJ, UK

corresponding Author spb@ecs.soton.ac.uk

\begin{abstract}
Textile supercapacitors are a key enabler of future, wireless, textile based smart wearables. With high power densities and long cycle lives, textile supercapacitors can be readily paired with energy harvesters to power the wearable technology. However, the energy density of these devices remains low (of the order of $\mu \mathrm{Wh}$ ) and work to increase this through improvements in the electrode design are requiring ever more complex materials and manufacturing processes. This work presents a novel and safe organic electrolyte that can increase the energy density of a simple symmetric activated carbon textile supercapacitor by $\sim 8$ times when compared to previous devices utilizing an identical substrate and set of electrodes. With a capacitance of $34.0 \mathrm{mF} . \mathrm{cm}^{-2}$ and an energy density of $18.9 \mu \mathrm{Wh} . \mathrm{cm}^{-2}$, this device showed excellent performance. The device also underwent a rarely seen test for calendar ageing and was found to still exhibit $48 \%$ capacitance retention after two months of calendar ageing. This novel electrolyte enables the production of high energy density electric double layer textile supercapacitors without the need for pseudocapacitve or battery-like electrode materials.
\end{abstract}

\section{Introduction}

Textile supercapacitors (TSCs) are seen as a complimentary technology with textile energy harvesters for the realization of wireless, and autonomous, electronic textiles (Etextiles). The TSC can store the energy harvested by the harvester (such as triboelectric ${ }^{1}$, piezoelectric ${ }^{2}$, thermoelectric ${ }^{3}, \mathrm{RF}^{4}$ ) and deliver the energy at a later date, decoupling the supply and demand within the e-textile. Textile based supercapacitors are favorable to the introduction of lumped components for these e-textiles as the devices can be embedded within the garment itself, allowing for seamless integration with the end user. Constructing the TSC within a textile substrate allows for a flexible device that increases the wearability 
and reduces the risk of component damage through bending, twisting and stretching 5 . The textile also greatly aids the electrode construction, with the fibrous nature of the textile acting as a scaffold for the electrode to deposit onto. These advantages have led to the significant increase in research activity in the field of TSCs over the past decade ${ }^{6}$. This research activity has been primarily focused on the electrode materials and compositions, both electric double layer (EDL) and pseudocapacitive. Typically EDL electrodes are formed of porous carbons (such as activated carbon ${ }^{7}$ ) or structured carbon (such as graphene ${ }^{8}$ ). In particular, activated carbon has been widely researched due to its pore size distribution and high surface area ${ }^{9}$. The meso length scale pores $(2-50 \mathrm{~nm})$ improve ion transport whereas the micro and nano pores $<2 \mathrm{~nm}$ improves the energy density ${ }^{10}$. However, high porosity can impair the movement of electrons through the electrode to the current collector and the greater the surface area of the carbon the higher the electrical resistance, leading to more loss. Whereas pseudocapacitive electrodes are typically made from conductive polymers (e.g. $\mathrm{PPy}^{11}$, $\mathrm{PANi}^{12}$ ) or transition metal oxides (predominantly $\mathrm{MnO}_{2}{ }^{13}$ ), though new structured materials such as MXenes ${ }^{14}$ are being introduced. EDL devices have demonstrated longer cycle lives, as well as increased power capabilities (as the energy is stored via a physical charge storage mechanism ${ }^{15}$ ) but lower capacitance and energy density, while the pseudocapacitive devices store more energy due to the fast faradaic reactions at the surface of the electrodes. However, these faradaic reactions, reduce the lifetime of the device (through shrinkage and swelling during cycling ${ }^{16}$ ) and have lower power/rate capabilities ${ }^{17}$. A significant amount of material science and electronic engineering has gone into the development of these electrode materials, focusing in particular on methods to minimize the drawbacks of the two electrode types while maximizing the benefits. This has led to some outstanding capacitance values being presented within the literature, with values as high as $3.1 \mathrm{~F}^{\mathrm{cm}} \mathrm{cm}^{-2}$ for electrodes (640 mF.cm ${ }^{-2}$ for the full cell) ${ }^{18}$. However, these extremely high capacitance devices often require multiple electrode materials and advanced production techniques that are unlikely to scale well in a commercial textile environment, limiting the widespread adoption of TSCs. A component of a TSC that has seen far less research interest is the electrolyte. This is surprising as the electrolyte dictates the device’s operating voltage and has a far more significant impact on the total energy density than the capacitance $\left(\mathrm{V}^{2}\right.$ compared to $\left.\mathrm{C}^{1}\right)$. With 
improvements in the electrolyte, an electrode with a lower electrochemical performance (eg: absolute capacitance), but simpler production methodology, could be utilized.

The electrolyte in TSCs should have a high ionic conductivity, large operating potential window as well as good cycling and temporal stability. Typically, aqueous electrolytes are seen in literature for TSC applications. Using water as the solvent for the electrolyte has distinct advantages, such as high ionic conductivity when the salt is incorporated and improved safety for the end user. Aqueous electrolytes have been demonstrated in alkaline, acidic and neutral solutions with the majority being produced from $\mathrm{KOH}^{19}, \mathrm{H}_{2} \mathrm{SO}_{4}{ }^{7}$ or $\mathrm{H}_{3} \mathrm{PO}_{4}{ }^{20}$. However, the potential window of the aqueous electrolytes are restricted by the electrolysis voltage of water, $1.23 \mathrm{~V}$. In practical applications this means multiple TSCs must be connected in series to achieve an appropriate voltage to operate with energy harvesters or the end use technology. This further limits the energy density by reducing the available capacitance as the total capacitance is the sum of the reciprocals of the individual devices. Wagih $e t$ al. ${ }^{21}$, for example, had to connect three TSCs in series in their textile power module, driven by a RF-harvesting rectenna. While Dong et $a{ }^{22}$ incorporated two yarn TSCs in series in their triboelectric nanogenerator system, though proposed the use of up to four. With more devices comes more complexity and consideration must be taken over the balancing within the TSC string. To increase the operating window for aqueous electrolytes, groups have made use of additives, (such as Bharathidasan et al. ${ }^{23}$ use of dispersed $\mathrm{SiO}_{\mathrm{x}}$ nano particles) or asymmetric electrodes (such as Guo et $\mathrm{al}^{24}$ use of nitrogen doped carbon sheets and $\mathrm{CoNiO}_{2}$ ). The $\mathrm{SiO}_{\mathrm{x}}$ nanoparticles led to a three times improvement in the energy density, while the asymmetric electrodes increased the potential window of the $\mathrm{KOH}$ electrolyte to $1.5 \mathrm{~V}$. However, these strategies again add complexity to the system.

Organic electrolytes are similar to aqueous electrolytes but use an organic solvent instead of water to dissolve the salt, increasing the operating potential significantly, up to $2.8 \mathrm{~V}^{25}$. The ionic conductivity of these electrolytes are, however, lower than that of aqueous electrolytes and concerns over the toxicity and flammability of the typical organic solvents have limited their use in TSCs. This has led to the majority of TSCs with organic electrolytes being seen in 
yarn-type supercapacitors due to the inherent encapsulation provided during the production process. Choi et al. ${ }^{26}$ used a tetraethylammonium tetrafluoroborate $\left(\mathrm{TEABF}_{4}\right)$ electrolyte with propylene carbonate (PC) as the solvent. This asymmetric yarn had an exceptional voltage range, up to $3.5 \mathrm{~V}$, and achieved a capacitance of $171 \mathrm{mF} . \mathrm{cm}^{-2}$. Keum et al. ${ }^{27}$ developed a symmetric, twisted-wire, yarn supercapacitor with a lithium perchlorate electrolyte with a dual solvent of PC and acetonitrile (ACN). This device had a voltage window of $1.5 \mathrm{~V}$, achieving a capacitance of $5.23 \mathrm{mF} . \mathrm{cm}^{-2}$. Park et al. ${ }^{28}$ also made use of a lithium perchlorate electrolyte with a dual solvent, within their TSC-biosensor device. Importantly, this device was not a yarn and was constructed as a multi-layered device, with further encapsulation used as a barrier between the end user and the ACN/PC solvent. This device had a maximum operating voltage of $2 \mathrm{~V}$ but was found to be optimal at $\sim 1.4 \mathrm{~V}$ and achieved a capacitance of $33.8 \mathrm{mF} . \mathrm{cm}^{-2}$. It is clear that the benefits of organic electrolytes, namely, high energy density and large operating potential, warrants further research focus than has been currently seen in the literature.

This work presents a novel organic electrolyte, one which makes use of dimethyl sulfoxide (DMSO, considered a green solvent ${ }^{29}$ ) as the solvent instead of ACN or PC. Much like the work of $\mathrm{Choi}^{26}$, $\mathrm{TEABF}_{4}$ has been chosen as the salt and polyacrylamide (PAM) will be the polymer element. It is widely seen that a gel polymer electrolyte is beneficial for TSCs, with the polymer helping to retain the liquid element, both in terms of reducing wicking throughout the bulk of the textile and to reduce evaporation. Polyvinyl alcohol (PVA) has been seen as the polymer of choice for many groups, owing to its solubility in water and ubiquity. However, previous work by the authors ${ }^{30}$ has shown catastrophic ageing (total failure after 3 days) of TSCs making use of PVA based electrolytes. Gao et al ${ }^{31}$ also demonstrated poor ageing of PVA based systems, attributed to dehydration of the electrolyte. The electrolytes were shown to crystallize with age, leading to a higher activation energy barrier for the ion transport. Whereas, PAM based electrolytes have shown good stability over time $^{32}$ and have also been successfully realized in other electrochemical systems ${ }^{33-35}$. The performance of the electrolyte will be benchmarked directly against previous works presented by the authors ${ }^{30,36}$ to compare against an identical electrode system, as well as the wider 
community. Importantly, absolute performance will not be the only test and a true ageing study will also be performed to investigate the ageing of an un-encapsulated device.

\section{Experimental}

\section{Materials}

Poly(ethylene-co-vinyl alcohol) (EVA), 1,2,4-Trichlorobenzene (1,2,4-TCB), Tetraethylammonium Tetrafluoroborate (TEABF4) and Polyacrylamide (PAM) were purchased from Sigma Aldrich. The YP80-F activated carbon and carbon black were purchased from Kuraray Co. and Chevron Phillips respectively. All chemicals were used as purchased.

\section{Preparation of electrode ink and electrolyte}

The carbon electrode ink was produced from activated carbon, carbon black, EVA and 1,2,4TCB. The carbon powders were mixed at a 9:1 ratio (activated carbon: carbon black) for a total mass of $0.85 \mathrm{~g}$, this ratio has previously been shown to be optimal for these devices ${ }^{37}$. The carbon black ratio is important to improve the electrical conductivity of the final electrode. $0.15 \mathrm{~g}$ of the EVA was dissolved in $5 \mathrm{ml}$ of 1,2,4-TCB before being added to the dry carbon mixture. The ink was then mixed at 1000 rpm for 3 minutes in a Hauschild Engineering speed mixer before being put into a Branson 1510 ultrasonic bath for one hour.

The electrolytes were prepared in similar ways. For the TEABF4|PAM electrolyte, $0.124 \mathrm{~g}$ of PAM was initially allowed to soak in $4 \mathrm{ml}$ of DMSO overnight before being heated under constant stirring via a magnetic bead set at 400 rpm until fully dissolved. Once fully incorporated, a $2 \mathrm{ml}$ solution of $\mathrm{TEABF}_{4}$ and DMSO was added dropwise with the direct heat turned off but the stirring continuing. This was allowed to cool to room temperature. For the $0.1,0.5$ and 1 M electrolyte solutions 130, 650 and 1300 mg of TEABF4 was used respectively.

\section{Supercapacitor assembly}

The electrode ink was deposited onto a plain weave cotton substrate via an airbrush following the method that has been discussed in detail previously ${ }^{36}$. The textile was clamped within an aluminum mask, with $1 \mathrm{~cm}$ diameter holes exposed. The airbrush was then set $7.5 \mathrm{~cm}$ away from the mask with a pressure of $20 \mathrm{psi}(138 \mathrm{kPa})$ and the first electrodes 
deposited $\left(0.785 \mathrm{~cm}^{2}\right.$ in area). The mask was then turned around and the second electrodes were deposited directly opposite the first, forming a single layer symmetric supercapacitor with the textile forming the separator layer. The supercapacitors were then cured at $100^{\circ} \mathrm{C}$ for 10 minutes. After this cure, the supercapacitors were weighed and found to have an electrode loading of approximately $2 \mathrm{mg}$ each. Once cured, the supercapacitors were vacuum impregnated with the gel electrolytes under a 50 mbar vacuum for 20 minutes. This impregnation method is to remove any trapped air within the structure of the textile and to improve the wetting of the electrolyte within the electrode structure. All cells were then housed within a Swagelok test cell as a two electrode system.

\section{Characterization}

The adhesion of the carbon to the textile and surface morphology was investigated by scanning electron microscope (SEM; Zeiss-EVO LS25). Brunauer-Emmett-Teller (BET) and Barret-Joyner-Halenda (BJH) measurements (Micromeritics Tristar || 3020) were performed using $\mathrm{N}_{2}$ to investigate the surface area and pore size distribution of the activated carbon. Prior to testing the sample was degassed at $80^{\circ} \mathrm{C}$ overnight. The electrochemical properties of the TSC were examined via cyclic voltammetry (CV), galvanostatic charge/discharge (GCD) and electrochemical impedance spectroscopy (EIS) on a Solartron 1470E Cell Test system at room temperature. All of the devices were characterized as two electrode systems and at room temperature. The areal capacitance, energy and power densities were calculated via equations 1, 2 and 3 respectively from the GCD results. The CV measurements were performed within the potential window of $0-2.0 \mathrm{~V}$ at scan rates of 5, 25, 50, 100 and $200 \mathrm{mV} / \mathrm{s}$, while the GCD measurements had a maximum voltage of $2.0 \mathrm{~V}$ and current densities of $0.25,0.5,1,1.5,2$ and $3 \mathrm{~mA} . \mathrm{cm}^{-2}$. The EIS measurements were performed over the frequency range of $250 \mathrm{kHz}-0.1 \mathrm{~Hz}$ with a voltage amplitude of $10 \mathrm{mV}$. The ionic conductivity of the electrolytes was characterized as described in the work of Huang et al ${ }^{38}$ and He et $\mathrm{al}^{39}$ by soaking a sample of the cotton $\left(0.785 \mathrm{~cm}^{2}, \sim 430 \mu \mathrm{m}\right.$ thick $)$ in the electrolyte before housing between stainless steel electrodes within a Swagelok cell to perform the EIS measurement. The actual conductivity was calculated from equation 4 . The electrochemical stability of the electrolyte was characterized through a potentiostatic hold measurement at 2.0 
and 2.4 V, with GCD cycling every 10 hours. The performance of the aged device was characterized via GCD at $1 \mathrm{~mA} \cdot \mathrm{cm}^{-2}$ with the device stored in air at $0 \mathrm{~V}$ in between measurements. The storage of the un-encapsulated device in air, under ambient conditions, was to demonstrate a worst case ageing and would be expected to be less severe in a packaged system. Previous studies of the carbon electrode system have shown good capacitance retention during mechanical bending ( $97.4 \%$ after 200 bending cycles $^{36}$ ) and as such has not been investigated in this work.

$$
\begin{gathered}
\mathrm{C}=\mathrm{I}\left(\frac{\mathrm{dV}}{\mathrm{dt}}\right)^{-1} \\
\mathrm{E}=\frac{1}{2} \mathrm{C} V_{\text {peak }}^{2} \\
\mathrm{P}=\frac{\mathrm{E}}{\mathrm{t}} \\
\sigma=\frac{\tau}{R \cdot A}
\end{gathered}
$$

Where $\mathrm{C}$ is the capacitance, $\mathrm{I}$ is the current, $\mathrm{dV} / \mathrm{dt}$ is the rate of change of voltage between $80 \%$ and $40 \%$ of $\mathrm{V}_{\text {peak }}(2.0 \mathrm{~V}$ for performance characterization and up to $2.4 \mathrm{~V}$ for voltage stability evaluation $)^{40,41}$, $\mathrm{E}$ is energy $(\mu \mathrm{Wh}), \mathrm{P}$ is power $(\mathrm{mW}), \sigma$ is conductivity $(\mathrm{mS} / \mathrm{cm}), \tau$ is the thickness of the cotton $(\mathrm{cm}), \mathrm{R}$ is the resistance $(\Omega)$ determined from the $\mathrm{x}$ axis intercept on the EIS plot and A is the area of the cotton sample $\left(\mathrm{cm}^{2}\right)$.

\section{Results and Discussion}

The YP80-F activated carbon was physically characterized via BET, BJH and SEM measurements and was found to have a surface area (SBET) of $1874.2 \mathrm{~m}^{2} / \mathrm{g}$. The adsorption and desorption isotherm is presented in Figure 1A and the pore size distribution presented in Figure $1 \mathrm{~B}$. The isotherm exhibits a type 1 characteristic $^{42,43}$, demonstrating a microporous structure within the carbon. The small hysteresis seen between the adsorption and desorption in the partial pressure range $0.6-1$ suggests a proportion of mesoporous structure ${ }^{43}$. This mixed pore scale is desired for EDL supercapacitor applications. The pore size distribution shows the majority of pores are within the range of $1.6-2.7 \mathrm{~nm}$, which straddles the micro 
and mesopore boundary ( $2 \mathrm{~nm}$ ) and explains the shape of the isotherm. Within the electrolyte, the $\mathrm{TEA}^{+}$ion is the largest with a bare ion radii of $\sim 4 \AA$ (estimated from a number of papers with possible quoted values within the range $0.339-0.425 \mathrm{~nm}^{44,45}$ ), when one considers the solvation shell (which could double the size of the ion ${ }^{46}$ ) the pore size distribution and ion size are seen to be highly compatible, with the predominant ion sizes approaching the length scale of the ions. The TEABF4 electrolyte is therefore suitable for a porous carbon TSC electrode of this kind.

The morphology of the carbon used for this study, and its adherence to the cotton substrate is presented in Figure 2 with 2A showing a magnification of 502 and 2B shows a magnification of 1.5k. Figure 2a shows a good uniform coverage of the carbon across the surface of the cotton. This coverage is shown to persist through the bulk of the carbon electrodes (left side of the image), creating a stable and uniform electrode for the TSC. The electrodes are however separated by a section of bare textile, as seen and discussed in previous work $^{36,37}$. Figure $2 \mathrm{~B}$ is more magnified, and shows the geometry of the carbon particles. It is seen that they resemble irregular polygons that overlap with each other partially, which aids the conductive additive in creating good electrical connections through the electrode. This is important as the carbon electrode itself forms the current collector. It can also been seen that very little of the fiber of the cotton yarn is seen, demonstrating excellent coverage during the manufacture process and exceptional adherence to the cotton.

With the material properties of the carbon established and the appropriateness of the manufacturing process confirmed the electrochemical properties of the $0.1,0.5$ and $1 \mathrm{M}$ electrolytes $\left(\mathrm{TEAB}_{4}\left|\mathrm{PAM}_{0.1}, \mathrm{TEAB}_{4}\right| \mathrm{PAM}_{0.5}\right.$ and $\left.\mathrm{TEAB}_{4} \mid \mathrm{PAM}_{1}\right)$ are presented in Figure 3. Figure 3A-F show that all three of the electrolytes behave very much as expected for EDL supercapacitors. The GCD curves (Figure 3A-C) demonstrate symmetric isosceles shaped profiles, with varying voltage drops at the point of current reversal. The voltage drop is associated to the equivalent series resistance (ESR) of the devices and was found to decrease with increased molar concentration (from $210 \Omega$ at $0.1 \mathrm{M}$ to $55 \Omega$ at $1.0 \mathrm{M}$ ). This high ESR in the device made from the $0.1 \mathrm{M}$ electrolyte caused instability at the highest discharge currents 
and limited the characterization to $2 \mathrm{~mA} . \mathrm{cm}^{-2}$. The CV curves (Figure 3D-F) show smooth, curved rectangular shapes with no obvious redox peaks. Figure 3G shows the conductivity of the electrolyte impregnated cotton substrate/separator. The conductivity is seen to increase with increasing molarity, however, doubling the molarity from 0.5 to $1 \mathrm{M}$ only saw an increase of $0.6 \mathrm{mS} . \mathrm{cm}^{-1}$. Figure 3H and 3I present the capacitance decay with increasing current density and the Ragone plot (respectively) for all three molarities. It can be seen that the $\mathrm{TEBF}_{4} \mid \mathrm{PAM}_{1}$ device achieved an excellent areal capacitance of $34.0 \mathrm{mF} . \mathrm{cm}^{-2}$ at 0.25 $\mathrm{mA} . \mathrm{cm}^{-2}$, reducing to $28.3 \mathrm{mF} . \mathrm{cm}^{-2}$ at $3 \mathrm{~mA} \cdot \mathrm{cm}^{-2}$. Though there is a decay in the overall capacitance due to the inability to utilize the full surface area of the electrode at the faster measurement rates, the device still performed well at higher current densities. The $\mathrm{TEABF}_{4} \mid \mathrm{PAM}_{0.5}$ electrolyte achieved $\sim 76 \%$ of this performance with a maximum capacitance of $25.9 \mathrm{mF} . \mathrm{cm}^{-2}$ and the TEABF $4 \mid \mathrm{PAM}_{0.1}$ achieving $52 \%$ of the $1 \mathrm{M}$ performance, with a maximum capacitance of $17.6 \mathrm{mF} \cdot \mathrm{cm}^{-2}$. The TEABF $4 \mid \mathrm{PAM}_{1}$ electrolyte is seen to have an exceptional energy density for its class $\left(18.9 \mu \mathrm{Wh} . \mathrm{cm}^{-2}\right.$ at $0.24 \mathrm{~mW} \cdot \mathrm{cm}^{-2}$ or $15.8 \mu \mathrm{Wh} . \mathrm{cm}^{-2}$ at $3.2 \mathrm{~mW} . \mathrm{cm}^{-2}$ ), with this attributed to the good capacitance and large operating potential window.

True inter-device comparison is rare due to differences in electrode composition, textile substrate and manufacturing processes. This makes direct comparison of the performance improvements due to an electrolyte challenging. Fortunately, previous work from the authors made use of the same ink formulation and textile substrate therefore can be directly compared (before a full comparison with the wider literature is presented at the end of this work in Table 1 and Figure 9). In the work of Yong et al. ${ }^{36}$ an ammonium dihydrogenphosphate|PVA (ADP|PVA) electrolyte was used, achieving a capacitance of $24.5 \mathrm{mF} . \mathrm{cm}^{-2}$ at $1.5 \mathrm{~mA} . \mathrm{cm}^{-2}$ compared to this work where the capacitance was $30.4 \mathrm{mF} . \mathrm{cm}^{-2}$. The original supercapacitor demonstrated an energy density of $2.2 \mu \mathrm{Wh} . \mathrm{cm}^{-2}$ compared to $16.9 \mu \mathrm{Wh} . \mathrm{cm}^{-2}$ achieved here, an increase of $\sim 8$ times. This immediately demonstrates the significance of this electrolyte and shows its benefits for simple carbon/carbon devices. High energy densities and good capacitances can be reached without the need for structured/exotic materials or difficult manufacturing processes. The increase in capacitance seen between the two works is attributed partially to better ion-pore size matching but mostly to the wetting of the electrode 
by the electrolyte. With the electrolyte better soaked into more of the pores, there will be better ion mobility, especially important at higher rates of charge-discharge. Figure 4 shows a qualitative evaluation of the wetting of the electrodes with the PVA|ADP electrolyte (Figure $4 \mathrm{~A}$ ) and the TEABF 4 PAM electrolyte (Figure 4B). For both electrodes a single drop of the electrolyte was dropped onto the surface and the image taken 5 seconds after that. As can be seen, the water based electrolyte forms a bead on the surface of the electrode while the organic electrolyte almost immediately wets the full electrode. There is clearly some hydrophobicity, probably caused by the rough surface of the electrode. This means greater effort is required to fully impregnate the electrode with the electrolyte and longer time is required for the TSC to be under vacuum for the aqueous system. Even then, it is difficult to know whether all of the small pores are fully filled with the electrolyte.

To further evaluate the $1 \mathrm{M}$ electrolyte, devices were characterized via GCD at a cut off voltage of 2.2 and $2.4 \mathrm{~V}$, with the coulumbic efficiency and energy density shown in Figure 5A and B respectively. Increasing the voltage threshold significantly increased the energy density, from 16.9 to $31.4 \mu \mathrm{Wh} . \mathrm{cm}^{-2}$. However, as the voltage limit increased the coulombic efficiency at the lower current levels decreased, with a minimum of $91.4 \%$ at $2.4 \mathrm{~V}$ while under a $0.25 \mathrm{~mA} . \mathrm{cm}^{-2}$ charge/discharge current density. This reduction of coulombic efficiency for textile supercapacitors is not uncommon at the lower current levels (for example, in the work of Yang et $\mathrm{al}^{7}$, their activated carbon coated fiberglass cloth had a charging time of $\sim 300 \mathrm{~s}$ compared to a total charge cycle of $\sim 565 \mathrm{~s}$ at $0.5 \mathrm{~mA} . \mathrm{cm}^{-2}$ ). This is often attributed to impurities within the device that are challenging to remove at the laboratory scale and higher intrinsic losses when compared to traditional supercapacitors. However, it is also seen in more traditional supercapacitors that use activated carbon electrodes, as in the work of Cheng et $\mathrm{al}^{47}$ where their activated carbon/nano-carbon traditional supercapacitor achieved a coulombic efficiency of $\sim 93 \%$ at $0.5{\mathrm{~A} . \mathrm{g}^{-1}}^{\mathrm{rising}}$ to $\sim 100 \%$ only at $10{\mathrm{~A} . \mathrm{g}^{-1}}^{-}$. To investigate the effect of this efficiency drop on the long term behavior of the device an ageing study and two voltage hold tests were performed (at 2.0 and $2.4 \mathrm{~V}$ ). Voltage hold tests are seen as more rigorous for determining the stability of a supercapacitor compared to cycling or voltage sweep testing as the device is held at the operating point, instead of temporarily entering the partially stable voltage region during 
cycling tests (as discussed in the works of Ruschhaupt et $\mathrm{al}^{48}$ and Weingarth et $\mathrm{al}^{49}$ ). Figure 6 shows the result of 90 hours of hold testing at the two voltage limits. Both voltages see an initial drop after 10 hours before the $2.0 \mathrm{~V}$ measurement plateaus above $70 \%$ capacitance retention for the remaining 80 hours, with an ESR increase of $<40 \%$. After 1 week of relaxation the device was re-measured and found to have retained $94 \%$ of the original capacitance, indicating the degradation was not permanent and unlikely to be decomposition of the electrolyte. The $2.4 \mathrm{~V}$ device however falls to an unstable plateau around $27 \%$ capacitance retention and a 360\% increase in ESR, returning to a 54\% capacitance after 1 week of rest. To the authors knowledge the use of the voltage hold characterization technique is the first for textile supercapacitors, and should be used more frequently within the community. These tests showed that though the device can operate at $2.4 \mathrm{~V}$, long term exposure to this voltage level could have significant effects to the device's lifetime and the wearable technology it is attached to, whereas, the device appears stable if operated up to $2.0 \mathrm{~V}$.

Ageing was chosen instead of cycle stability (to assess the stability of the electrolyte) as the effect of ageing is rarely characterized but has a more fundamental effect on the device, and is more representative of the real world usage, complimenting the voltage hold testing. The device was tested after 1 day, 2 days, 1 week, 2 weeks, 1 month and 2 month intervals and between tests was stored in air. The GCD results can be seen in Figure 7, and further EIS analysis shown in Figure 8. It can be seen that the device was still operational after the two month period, with a capacitance retention of $48 \%$, while the coulombic efficiency fell from $97 \%$ to $88 \%$. When this is compared to previous work ${ }^{30}$ on similar aqueous devices this is a vast improvement (>19 times) as previous devices failed (zero capacitance) after only three days of being exposed to similar ageing tests. The equivalent series resistance was found to rise from $56 \Omega$ to $254 \Omega$ over the period of investigation and suggests a partial dehydration of the electrolyte, leading to an increase in resistance. This is supported by the EIS measurements that show only a small increase in the initial resistance of the device (the Z' intercept) but a large increase in the electrolyte resistance. The high frequency region of the EIS plot shows a depressed semi-circle, which is best modelled as a constant phase element and resistor in parallel, sometimes referred to as a Cole element. The CPE's impedance is 
seen in equation 5 , with the $\mathrm{p}(0 \leq \mathrm{p} \leq 1)$ term representing the behavior of the device with 0 being a resistor and 1 an ideal capacitor. Within the device this value dropped from 0.66 to 0.49 and the parallel resistance rose from $39.4 \Omega$ to $685 \Omega$. Though ageing is seen within the device, it is far less catastrophic than that seen in previous studies and sets a good benchmark for future electrolytes and TSC devices. The use of both ageing and voltage hold testing are seen as complimentary techniques and when combined give a greater understanding of the electrochemical and temporal stability of the TSC.

$$
\mathrm{Z}_{\text {cpe }}=\frac{1}{\mathrm{~T}(\mathrm{i} \omega)^{\mathrm{n}}}
$$

Where $\mathrm{Z}$ is the impedance, $\mathrm{T}$ is the CPE parameter ${ }^{50}, \mathrm{i}$ is $\sqrt{-1}, \omega$ is the angular frequency and $\mathrm{n}$ is a value between 0 and 1 .

Direct comparison with previous work of similar devices is important to validate the absolute improvement in the device performance due to the electrolyte alone, however, comparison with devices within the community is also required. Table 1 shows a detailed comparison with similar devices while Figure 9 benchmarks the device against the results of the wider community, not just porous carbon devices. Though similar devices achieved higher capacitances than the values reported in this work, the energy densities were lower due to the exceptional performance of the TEABF4|PAM electrolyte compared to those used in the other works. From Figure 9 it can be seen that the devices produced within this study are comparable to the highest energy density devices seen in literature. It is only the work of Shang et al. ${ }^{51}$ and Yang et al. ${ }^{52}$ that shows significant improvement but these make use of soft hybrid scaffolding and multi-walled carbon nanotubes-reduced graphene oxide (respectively). These are expensive techniques and materials compared to the ones used within this study, questioning their viability for real-world devices.

\section{Conclusions}

Increasing the energy density of TSCs is a fundamental challenge that must be overcome before wide spread adoption of the technology can be realized. Typically, improvements have focused on the electrode material and production methodology. However, this work has 
successfully increased the energy density of a simple carbon/carbon TSC by $\sim 8$ times (compared to previously researched devices), through the development of a novel organic electrolyte. Through the use of a green solvent, a safe organic electrolyte has been demonstrated, which can be produced simply in a one-pot methodology. The TSC is seen to have a stable operating potential of $2.0 \mathrm{~V}$, an areal capacitance of $34.0 \mathrm{mF} . \mathrm{cm}^{-2}$ and an exceptional energy density of $18.9 \mu \mathrm{Wh} . \mathrm{cm}^{-2}$ at $0.24 \mathrm{~mW} . \mathrm{cm}^{-2}$. The energy density places these TSCs at the top of EDL carbon devices and is comparable to many pseudocapactive/supercapattery devices. Under ageing testing the device retained $48 \%$ of its capacitance over a two month period. Furthermore, the device achieved a $>70 \%$ capacitance retention after 90 hours of $2.0 \mathrm{~V}$ hold testing, with a $<40 \%$ rise in the ESR (before returning to $94 \%$ of the original capacitance after a rest period of 1 week). Though more laborious, ageing testing of this sort should be considered more widely in the community to better understand the long term behavior of TSCs. Significant work has explored the fundamental nature of $\mathrm{TEABF}_{4}$ electrolytes in $\mathrm{ACN}$ or PC solvents, so future work will focus on understanding the solvation and chemical properties of the electrolyte with DMSO. More work must also be undertaken to further extend the calendar life of these devices, through the investigation of dual polymer gels and their effects on electrolyte retention.

\section{Acknowledgments}

The authors would like to thank the Engineering and Physical Sciences Research Council (EPSRC) for their help with this work under the grants EP/L016818/1 and EP/P010164/1 as well as the United State Army under contract no. W911NF2010324. This work was also supported by the Royal Academy of Engineering under the Chairs in Emerging Technologies scheme. The authors would also like to thank Dr. Nikolay Zhelev for his help with the BET and BJH characterization. Supporting data is available from the University of Southampton Institutional repository on request from http://dx.doi.org/10.5258/SOTON/D1902

\section{References}

1. Z. Tian, J. He, X. Chen, Z. Zhang, T. Wen, C. Zhai, J. Han, J. Mu, X. Hou, X. Chou, and C. Xue, Nano Energy, 39 562-570 (2017). 
2. S. Anwar, M. Hassanpour Amiri, S. Jiang, M. M. Abolhasani, P. R. F. Rocha, and K. Asadi, Advanced Functional Materials, 31 (4), 2004326 (2021).

3. A. Lund, Y. Tian, S. Darabi, and C. Müller, Journal of Power Sources, 480228836 (2020).

4. M. Wagih, A. S. Weddell, and S. Beeby, IEEE Transactions on Antennas and Propagation, 69 (5), 2522-2536 (2021).

5. A. S. Ghouri, R. Aslam, M. S. Siddiqui, and S. K. Sami, Frontiers in Materials, 758 (2020).

6. $\quad$ N. Hillier, S. Yong, and S. Beeby, Energy Reports, 6 148-156 (2020).

7. C. Yang, L. Hu, L. Zang, Q. Liu, J. Qiu, J. Yang, and X. Qiao, Journal of The Electrochemical Society, 167 (2), 020540 (2020).

8. A. M. Abdelkader, N. Karim, C. Vallés, S. Afroj, K. S. Novoselov, and S. G. Yeates, 2D Materials, 4 (3), 035016 (2017).

9. T. Otowa, Y. Nojima, and T. Miyazaki, Carbon, 35 (9), 1315-1319 (1997).

10. J. Chmiola, G. Yushin, R. Dash, and Y. Gogotsi, Journal of Power Sources, 158 (1), $765-772$ (2006).

11. S. Huang, P. Chen, W. Lin, S. Lyu, G. Chen, X. Yin, and W. Chen, RSC Advances, 6 (16), 13359-13364 (2016).

12. Y. Li and C. Chen, Journal of Materials Science, 52 (20), 12348-12357 (2017).

13. Y. Wang, X. Li, Y. Wang, Y. Liu, Y. Bai, R. Liu, and G. Yuan, Electrochimica Acta, 299 12-18 (2019).

14. Z. Wang, S. Qin, S. Seyedin, J. Zhang, J. Wang, A. Levitt, N. Li, C. Haines, R. Ovalle-Robles, W. Lei, Y. Gogotsi, R. H. Baughman, and J. M. Razal, Small, 14 (37), 1802225 (2018).

15. A. Davies and A. Yu, The Canadian Journal of Chemical Engineering, 89 (6), 1342-1357 (2011).

16. Z.-z. Zhu, G.-c. Wang, M.-q. Sun, X.-w. Li, and C.-z. Li, Electrochimica Acta, 56 (3), 1366-1372 (2011).

17. A. González, E. Goikolea, J. A. Barrena, and R. Mysyk, Renewable and Sustainable Energy Reviews, 58 1189-1206 (2016).

18. Y. Zhou, X. Wang, L. Acauan, E. Kalfon-Cohen, X. Ni, Y. Stein, K. K. Gleason, and B. L. Wardle, Advanced Materials, 31 (30), 1901916 (2019).

19. W. Zhang, R. Guo, J. Sun, L. Dang, Z. Liu, Z. Lei, and Q. Sun, Journal of Colloid and Interface Science, 553 705-712 (2019).

20. Z. Stempien, M. Khalid, M. Kozicki, M. Kozanecki, H. Varela, P. Filipczak, R. Pawlak, E. Korzeniewska, and E. Sąsiadek, Synthetic Metals, 256116144 (2019).

21. M. Wagih, N. Hillier, S. Yong, A. S. Weddell, and S. Beeby, IEEE Open Journal of Antennas and Propagation, 2 302-314 (2021).

22. K. Dong, Y.-C. Wang, J. Deng, Y. Dai, S. L. Zhang, H. Zou, B. Gu, B. Sun, and Z. L. Wang, ACS Nano, 11 (9), 9490-9499 (2017).

23. P. Bharathidasan, T. Subramaniam, D. Chandini, S. Sivakkumar, K. Rajan, and S. Devaraj, Journal of the Electrochemical Society, 167 (14), 140524 (2020).

24. R. Guo, J. Li, Y. Jia, F. Xin, J. Sun, L. Dang, Z. Liu, and Z. Lei, Journal of Materials Chemistry A, 7 (8), 4165-4174 (2019).

25. S. Alipoori, S. Mazinani, S. H. Aboutalebi, and F. Sharif, Journal of Energy Storage, 27101072 (2020).

26. C. Choi, J. W. Park, K. J. Kim, D. W. Lee, M. J. de Andrade, S. H. Kim, S. Gambhir, G. M. Spinks, R. H. Baughman, and S. J. Kim, RSC Advances, 8 (24), 13112-13120 (2018).

27. K. Keum, G. Lee, H. Lee, J. Yun, H. Park, S. Y. Hong, C. Song, J. W. Kim, and J. S. Ha, ACS Applied Materials \& Interfaces, 10 (31), 26248-26257 (2018).

28. H. Park, J. W. Kim, S. Y. Hong, G. Lee, H. Lee, C. Song, K. Keum, Y. R. Jeong, S. W. Jin, D. S. Kim, 
and J. S. Ha, ACS Nano, 13 (9), 10469-10480 (2019).

29. S. Hosseini, A. Abbasi, L.-O. Uginet, N. Haustraete, S. Praserthdam, T. Yonezawa, and S. Kheawhom, Scientific Reports, 9 (1), 14958 (2019).

30. N. Hillier, S. Yong, and S. Beeby, in "2019 19th International Conference on Micro and Nanotechnology for Power Generation and Energy Conversion Applications (PowerMEMS)", p. 1-5, 2019.

31. H. Gao, J. Li, and K. Lian, RSC Advances, 4 (41), 21332-21339 (2014).

32. Z. Li, M. Li, Q. Fan, X. Qi, L. Qu, and M. Tian, ACS Applied Materials \& Interfaces, 13 (12), 1477814785 (2021).

33. P. Sun, M. Qiu, M. Li, W. Mai, G. Cui, and Y. Tong, Nano Energy, 55 506-515 (2019).

34. Y. Huang, M. Zhong, F. Shi, X. Liu, Z. Tang, Y. Wang, Y. Huang, H. Hou, X. Xie, and C. Zhi, Angewandte Chemie International Edition, 56 (31), 9141-9145 (2017).

35. M. J. Tan, B. Li, P. Chee, X. Ge, Z. Liu, Y. Zong, and X. J. Loh, Journal of Power Sources, $400566-$ 571 (2018).

36. S. Yong, J. Owen, and S. Beeby, Advanced Engineering Materials, 20 (5), 1700860 (2018).

37. N. Hillier, S. Yong, and S. Beeby, Journal of Physics: Conference Series, 1407012059 (2019).

38. Q. Huang, D. Wang, H. Hu, J. Shang, J. Chang, C. Xie, Y. Yang, X. Lepró, R. H. Baughman, and Z. Zheng, Advanced Functional Materials, 30 (27), 1910541 (2020).

39. T. He, R. Jia, X. Lang, X. Wu, and Y. Wang, Journal of The Electrochemical Society, 164 (13), E379E384 (2017).

40. Y. Ge, X. Xie, J. Roscher, R. Holze, and Q. Qu, Journal of Solid State Electrochemistry, 24 (11), 32153230 (2020).

41. British Standards Institution, in "BS EN 62391-1:2016: Fixed electric double-layer capacitors for use in electric and electronic equipment. Generic specification". BSI, 2016.

42. M. Ahmed, M. A. Islam, M. Asif, and B. Hameed, Bioresource technology, 243 778-784 (2017).

43. M. Thommes, K. Kaneko, A. V. Neimark, J. P. Olivier, F. Rodriguez-Reinoso, J. Rouquerol, and K. S. W. Sing, Pure and Applied Chemistry, 87 (9-10), 1051-1069 (2015).

44. C. Decaux, C. Matei Ghimbeu, M. Dahbi, M. Anouti, D. Lemordant, F. Béguin, C. Vix-Guterl, and E. Raymundo-Piñero, Journal of Power Sources, 263 130-140 (2014).

45. M. Ue, Journal of The Electrochemical Society, 141 (12), 3336-3342 (1994).

46. G. Feng, J. Huang, B. G. Sumpter, V. Meunier, and R. Qiao, Physical Chemistry Chemical Physics, 12 (20), 5468-5479 (2010).

47. $\quad$ F. Cheng, X. Yang, S. Zhang, and W. Lu, Journal of Power Sources, 450227678 (2020).

48. P. Ruschhaupt, S. Pohlmann, A. Varzi, and S. Passerini, Batteries \& Supercaps, 3 (8), 698-707 (2020).

49. D. Weingarth, A. Foelske-Schmitz, and R. Kötz, Journal of Power Sources, $22584-88$ (2013).

50. P. Córdoba-Torres, Electrochimica Acta, 225 592-604 (2017).

51. J. Shang, Q. Huang, L. Wang, Y. Yang, P. Li, and Z. Zheng, Advanced Materials, 32 (4), 1907088 (2020).

52. Y. Yang, Q. Huang, L. Niu, D. Wang, C. Yan, Y. She, and Z. Zheng, Advanced Materials, 29 (19), 1606679 (2017).

53. S. Tan and K. D. Li-Oakey, Journal of The Electrochemical Society, 166 (14), A3294-A3304 (2019).

54. P.-W. Xiao, Q. Meng, L. Zhao, J.-J. Li, Z. Wei, and B.-H. Han, Materials \& Design, 129 164-172 (2017).

55. X. Li, L. Yuan, R. Liu, H. He, J. Hao, Y. Lu, Y. Wang, G. Liang, G. Yuan, and Z. Guo, Advanced 
Energy Materials, 11 (12), 2003010 (2021).

56. H. Xu, X. Hu, H. Yang, Y. Sun, C. Hu, and Y. Huang, Advanced Energy Materials, 5 (6), 1401882 (2015).
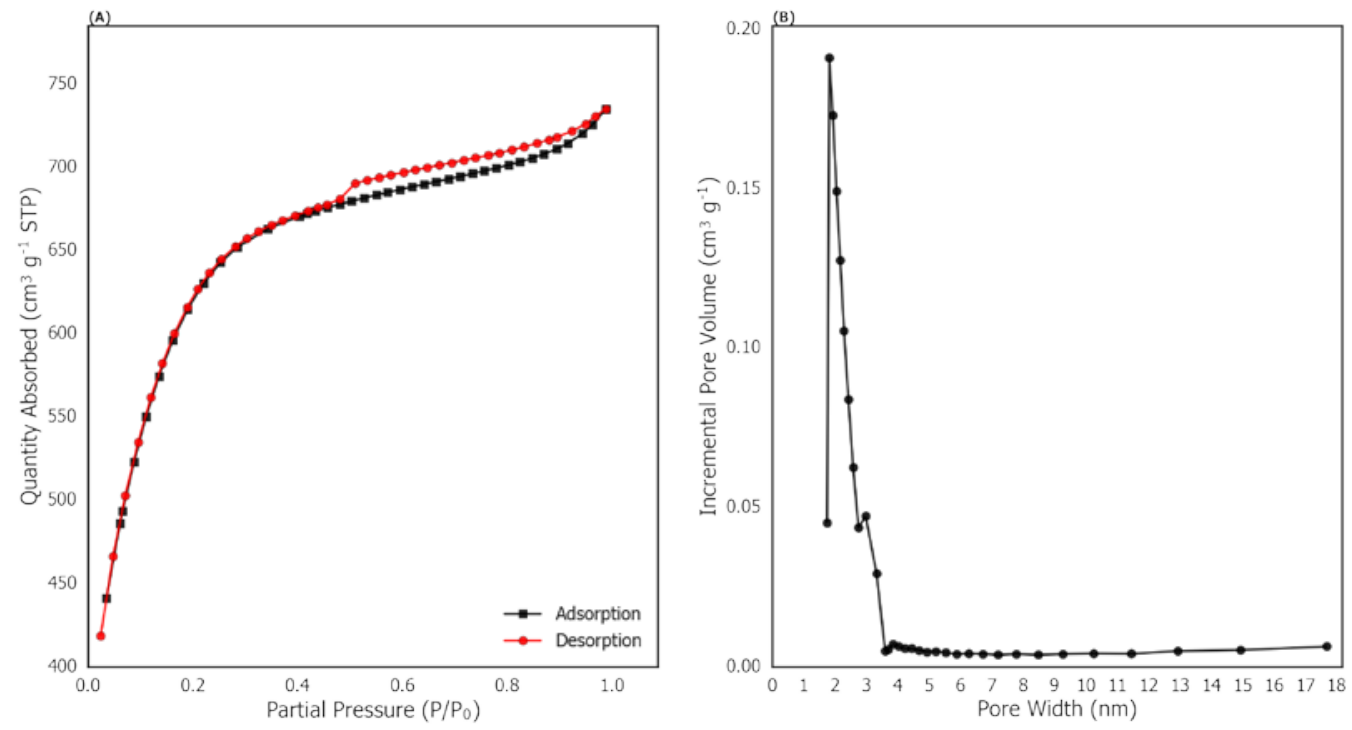

Figure 1: Nitrogen adsorption-desorption isotherm (A) and pore size distribution (B) of the YP80-F activated carbon at $77 \mathrm{~K}$.
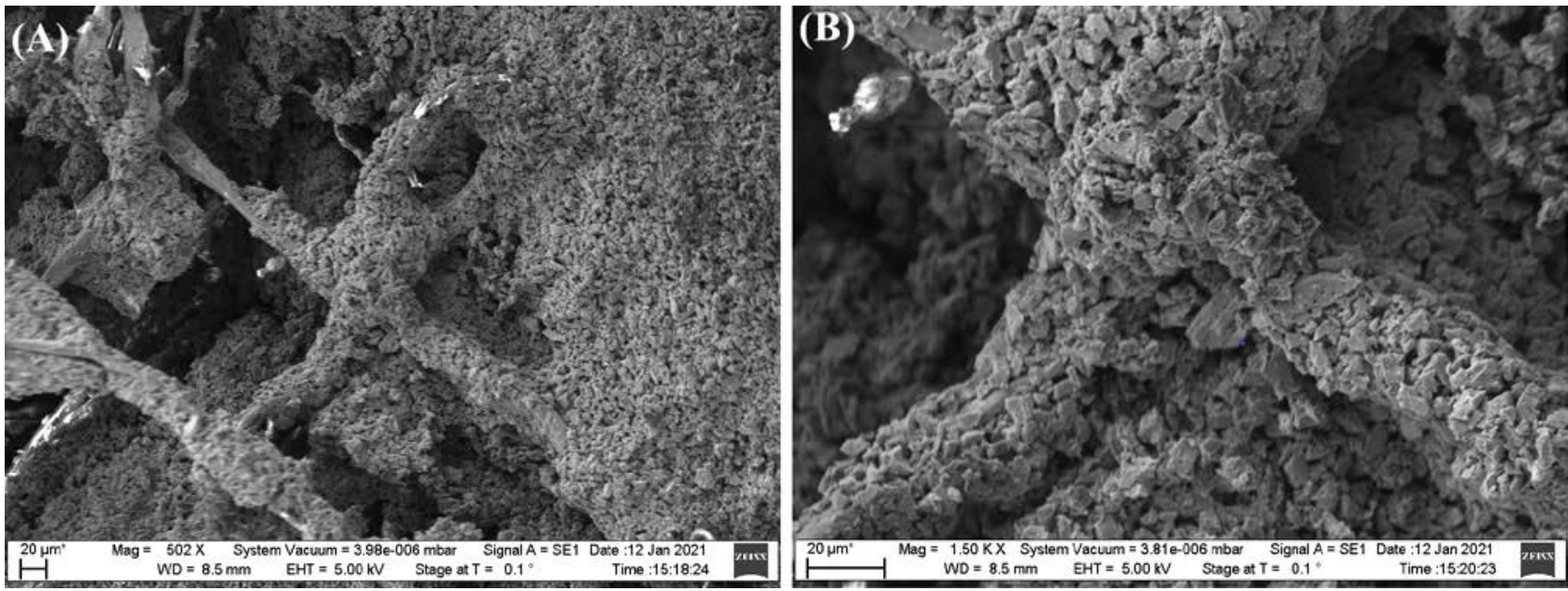

Figure 2: SEM images of the carbon ink deposited on the surface of the cotton (A) and the adherence of the electrode ink to the individual fibers (B). A consistent coating is observed 
across the surface in (A) while (B) shows the morphology and variation seen within the carbon particles. Good adherence and coverage is seen in both images.
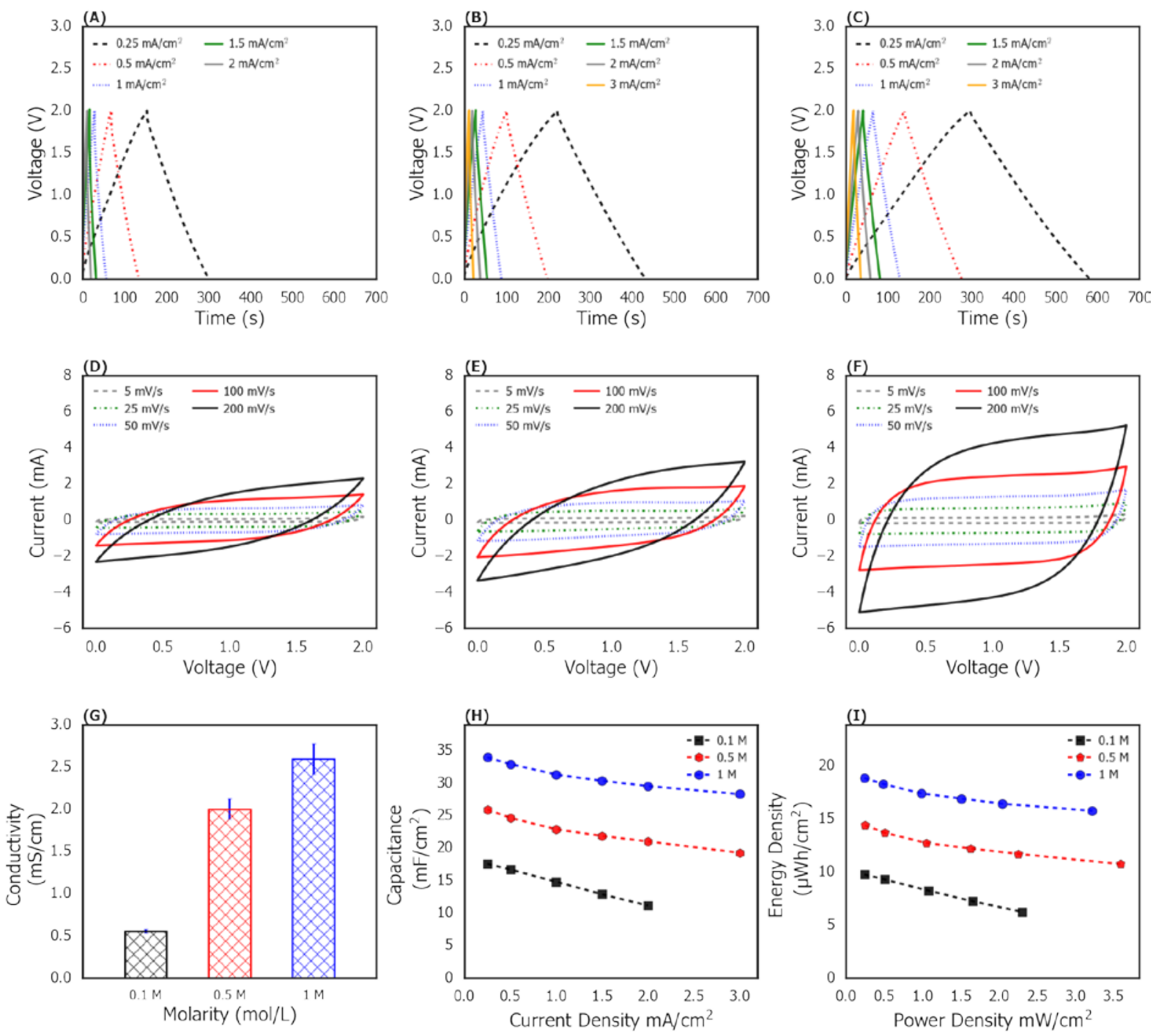

Figure 3: Electrochemical properties of the activated carbon/activated carbon TSCs with varying molarities of the TEABF $4 \mid$ PAM electrolyte. GCD curves of (A) $0.1 \mathrm{M}$, (B) $0.5 \mathrm{M}$ and (C) 1 at current densities of $0.25-3 \mathrm{~mA} \cdot \mathrm{cm}^{-2}$. CV curves of (D) $0.1 \mathrm{M}$, (E) $0.5 \mathrm{M}$ and (F) 1 $\mathrm{M}$ at scan rates of $5-200 \mathrm{mV} / \mathrm{s}$. (G) is the ionic conductivity of the electrolyte soaked cotton substrate characterized via EIS, there error bars are the standard error from three samples with 5 repeats each. $(\mathrm{H})$ Capacitance degradation with increasing measurement current (I) Ragone plot of the devices made from the three molarities of electrolyte. 


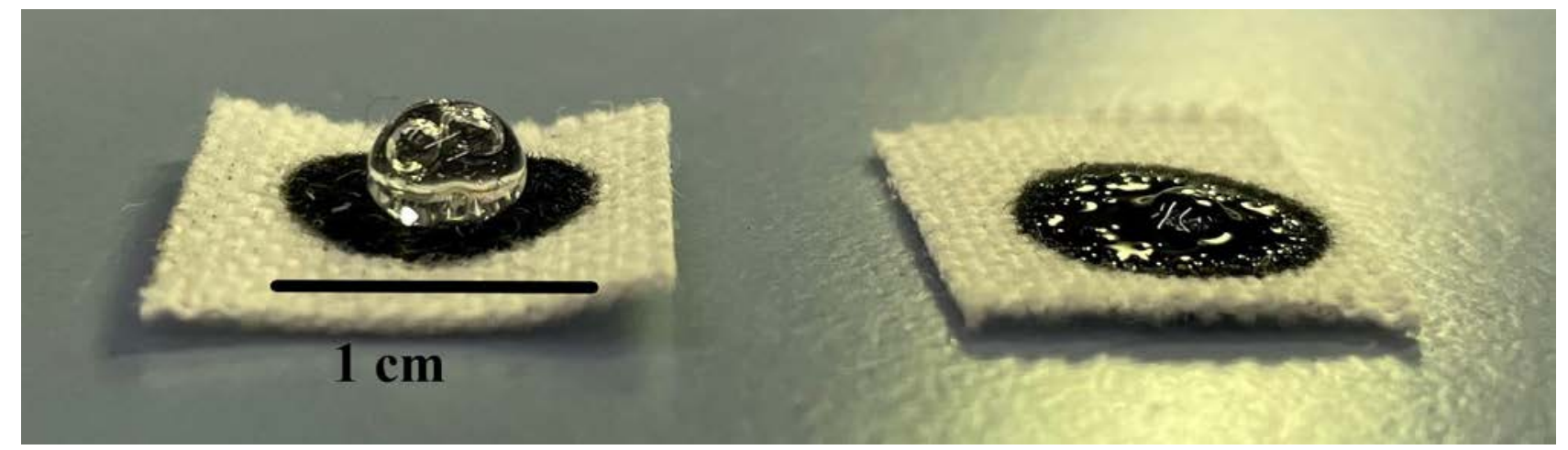

Figure 4: Image of a qualitative wetting experiment between aqueous ammonium dihydrogenphophate|PVA electrolyte (Left) and TEABF4|PAM electrolytes (Right) on two representative carbon electrodes produced identically as those used for the devices in this work.
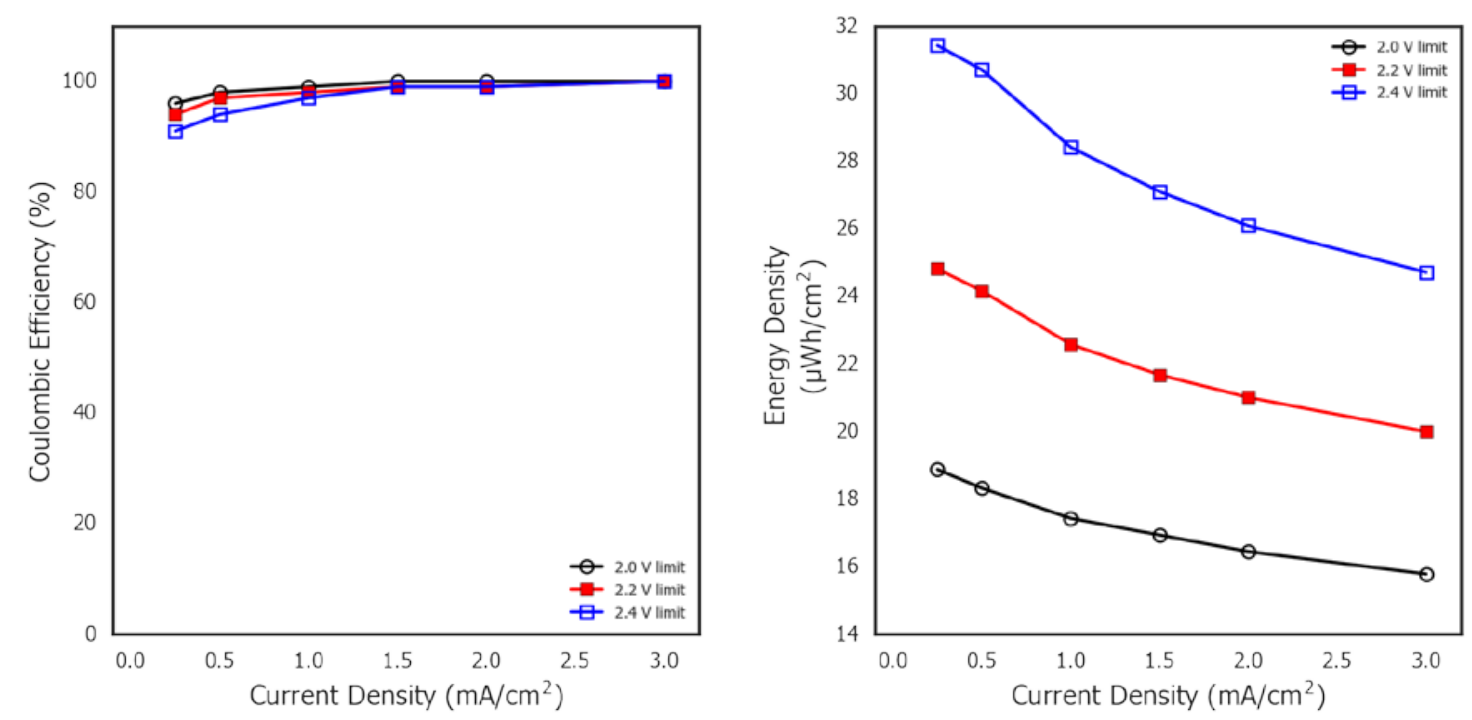

Figure 5: Coulombic effiency and energy density of the $1 \mathrm{M}$ devices when characterized via GCD measurements at cut off voltages of 2.0, 2.2 and $2.4 \mathrm{~V}$. 


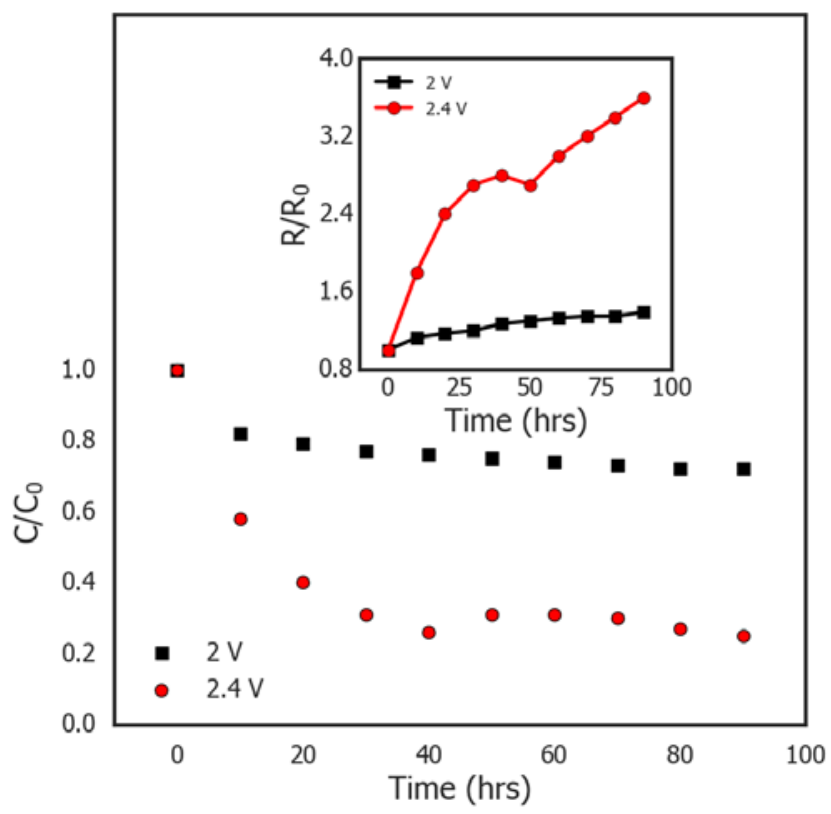

Figure 6: Capacitance degradation during voltage hold testing at 2.0 and $2.4 \mathrm{~V}$ over a 90 hour period. The insert is the ESR of the devices characterized over the same cycles as the capacitance. All values are the average of five cycles.

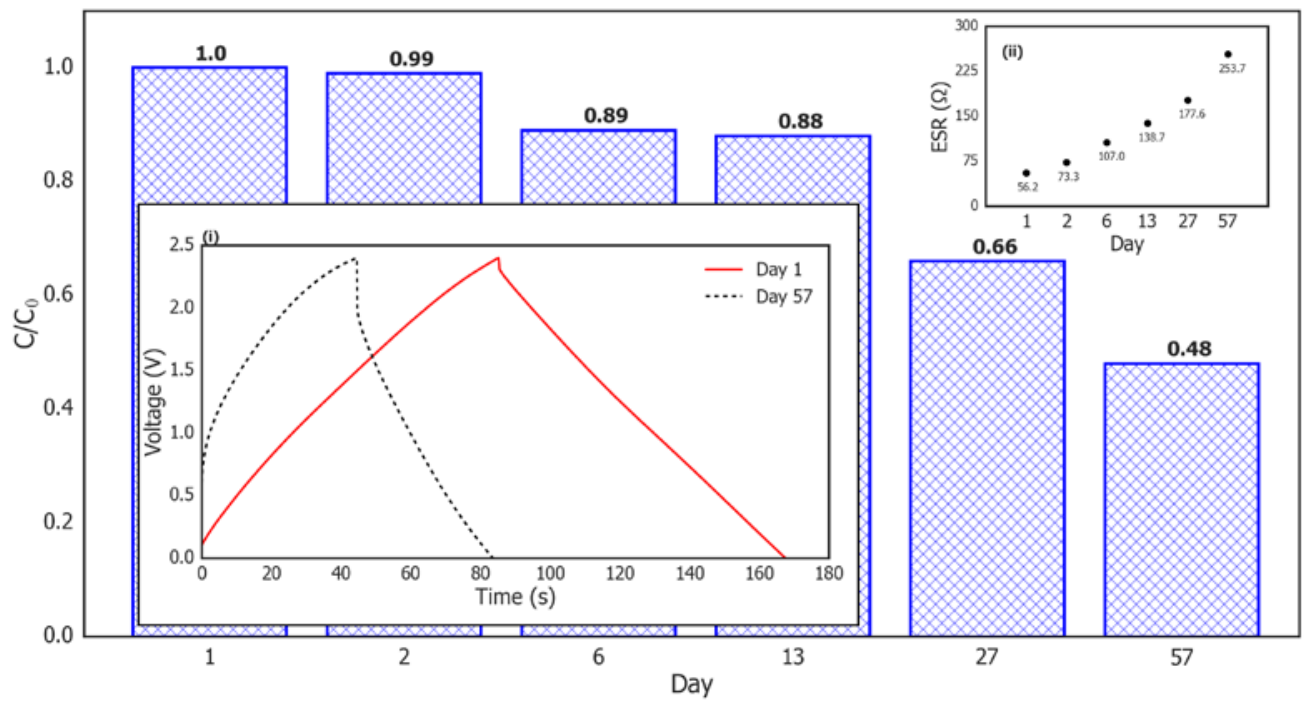

Figure 7: Normalized capacitance determined from GCD testing of a TEABF4|PAM $\mathrm{PM}_{1}$ device at $1 \mathrm{~mA} \cdot \mathrm{cm}^{-2}$ at intervals over a two month period. The insert (i) is the GCD trace on the first day versus that of the $57^{\text {th }}$ day. Insert (ii) is the ESR change over the two month period. 


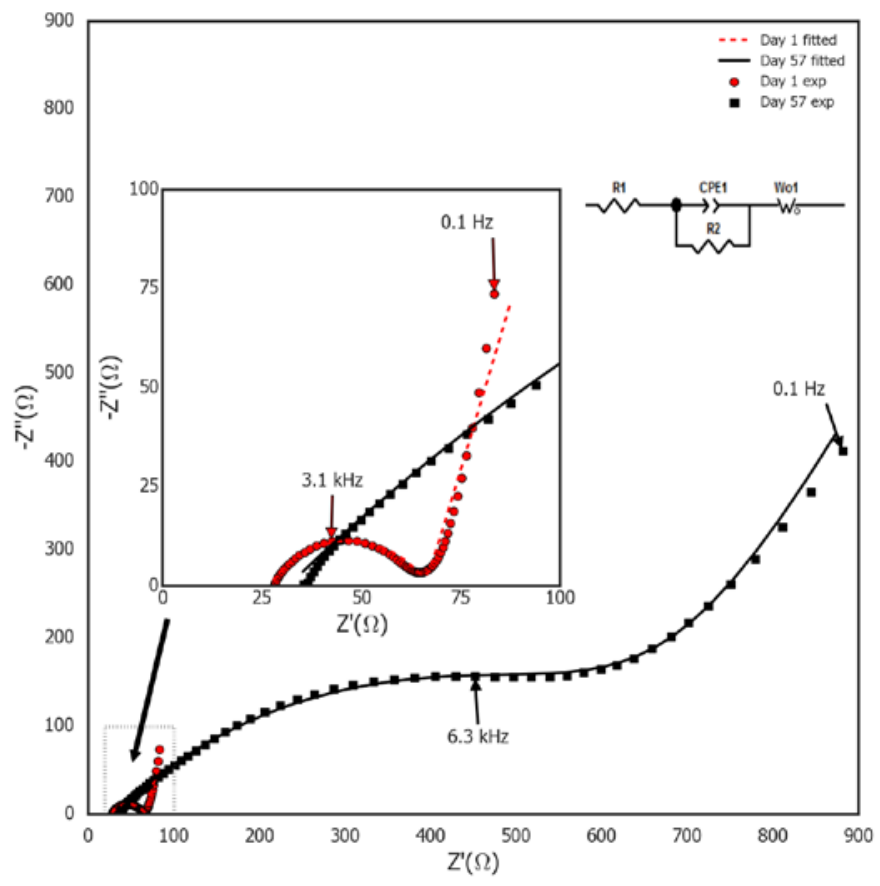

Figure 8: EIS measurement for the TEABF $4 \mid \mathrm{PAM}_{1}$ device at day 1 and day 57 . The insert is a magnified view of the graph over the range $0-100 \Omega$ with the fitting model also shown on the figure. 
Table 1: Detailed comparison of similar devices to the work presented in this paper.

\begin{tabular}{|c|c|c|c|c|}
\hline Reference & $\begin{array}{l}\text { Electrode } \\
\text { Material }\end{array}$ & Electrolyte & $\begin{array}{l}\text { Capacitance } \\
\left(\mathrm{mF} \cdot \mathrm{cm}^{-2}\right)\end{array}$ & $\begin{array}{l}\text { Energy density } \\
\left(\mu \mathrm{Wh} . \mathrm{cm}^{-2}\right)\end{array}$ \\
\hline Yang et $\mathrm{al}^{7}$ & $\begin{array}{c}\text { Activated } \\
\text { carbon and } \\
\text { asphalt }\end{array}$ & $\mathrm{H}_{2} \mathrm{SO}_{4} \mid \mathrm{PVA}$ & 85.4 & 7.6 \\
\hline Zhang et al ${ }^{19}$ & $\begin{array}{l}\text { Activated } \\
\text { carbon }\end{array}$ & $\mathrm{KOH} \mid \mathrm{PVA}$ & 153 & 21.2 \\
\hline Tan et $\mathrm{al}^{53}$ & $\begin{array}{c}\text { Carbon } \\
\text { nanofibers }\end{array}$ & $\mathrm{KOH}$ & 150 & 15 \\
\hline Xiao et $\mathrm{al}^{54}$ & $\begin{array}{l}\text { Cotton derived } \\
\text { porous carbon } \\
\text { Cotton-Flax } \\
\text { derived porous } \\
\text { carbon }\end{array}$ & $\mathrm{H}_{2} \mathrm{SO}_{4}$ & $\begin{array}{l}38 \\
97\end{array}$ & $\begin{array}{l}3.4^{\ddagger} \\
8.6^{\ddagger}\end{array}$ \\
\hline This work & $\begin{array}{l}\text { Activated } \\
\text { carbon }\end{array}$ & $\mathrm{TEABF}_{4} \mid \mathrm{PAM}$ & $\begin{array}{l}(2.0 \mathrm{~V}) 34.0 \\
(2.4 \mathrm{~V}) 39.3\end{array}$ & $\begin{array}{l}18.9 \\
31.4\end{array}$ \\
\hline
\end{tabular}

${ }^{\ddagger}$ Calculated using the potential window of $0.8 \mathrm{~V}$.

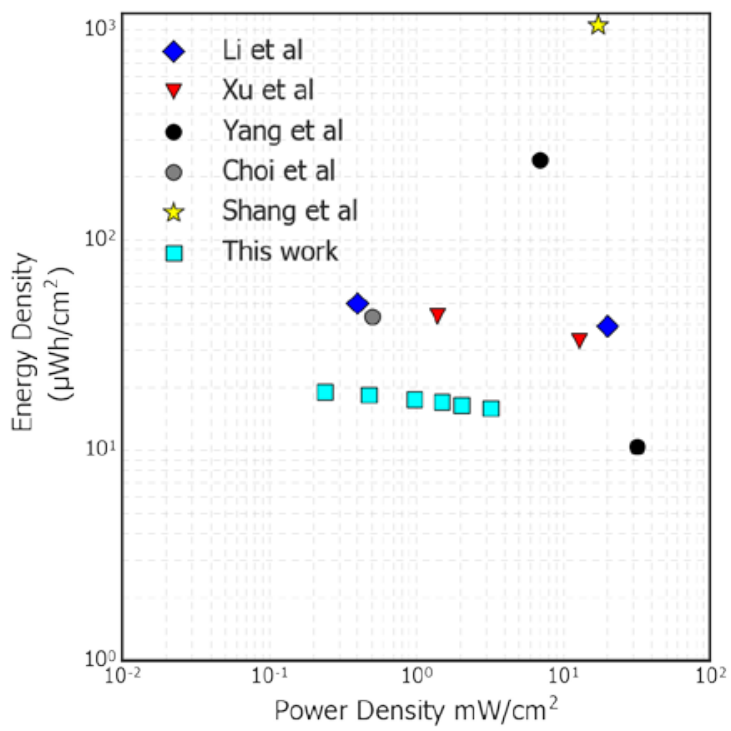

Figure 9: Ragone plot of high energy density textile supercapacitors. Data taken from Li et $\mathrm{al}^{55}$, Xu et $\mathrm{al}^{56}$, Yang et $\mathrm{al}^{52}$, Choi et $\mathrm{al}^{26}$ and Shang et al. ${ }^{51}$ 